\title{
IRRIGATION DEVELOPMENT AND MANAGEMENT IN GHANA: PROSPECTS AND CHALLENGES
}

\author{
N. Kyei-Baffour and E. Ofori \\ Department of Agricultural Engineering, Faculty of Mechanical and \\ Agricultural Engineering, College of Engineering, \\ KNUST, Kumasi
}

\begin{abstract}
Agriculture plays a vital role in the national economy but it is predominantly dependent on natural rainfall. Irrigated agriculture on a fairly limited scale is a recent phenomenon and was necessitated largely by the seasonality and unreliability of natural rainfall. The development and management of irrigation, however, has been characterised by difficulties notably weak database, excessive cost, environmental problems and extreme pessimism in some quarters since rainfed agriculture is seen as potentially able to support the present population. Irrigation capacity utilisation on existing schemes is very low and reasons for this situation are put forward, as well as the broad policy objectives needed to promote irrigation development and management. Water management is seen as a serious drawback on existing schemes. It is envisaged that irrigation will be seen in its right perspective as a multidisciplinary activity to ensure the success of schemes. There is the need for running a postgraduate programme in irrigation at the KNUST to enhance the nations efforts at developing and managing irrigation projects successfully.
\end{abstract}

Keywords: Irrigation, Development, Management, Capacity utilisation, Policies

\section{INTRODUCTION}

Agriculture is vital for the overall economic development of Ghana since it is the largest contributor to Gross Domestic Product (GDP) accounting for about $50 \%$. It also accounts for about $60 \%$ of export earnings and directly or indirectly supports $80 \%$ of the total population economically through farming, distribution of farm products and provision of other services to the agricultural sector (MOFA, 1991). A vital area necessary for the modernisation of agriculture in Ghana is irrigation. Unfortunately, the total area under irrigation as at 1996 was estimated at 11,000 ha which formed only $0.44 \%$ of the total land area (Sant' Anna, 1997) or just $0.26 \%$ of area under cultivation. According to Memuna and Cofie (2005), this has barely changed ( See also Figure 1) and this goes to buttress the fact that agriculture is mainly rainfed, subject to the vagaries of the weather despite the fact that yields are greater and cropping is twice yearly on some irrigated schemes. The existing irrigation projects are distributed in all the six distinct agro-ecological zones.

The aim of this paper is to put irrigation development and management into its proper past and contemporary historical perspectives, assign reasons for the low capacity utilisation even on existing schemes and to examine what can be done including broad policy objectives to make the impact of irrigation felt on the national economy. Capacity utilisation relates the net to the potential area that can be irrigated by the scheme.

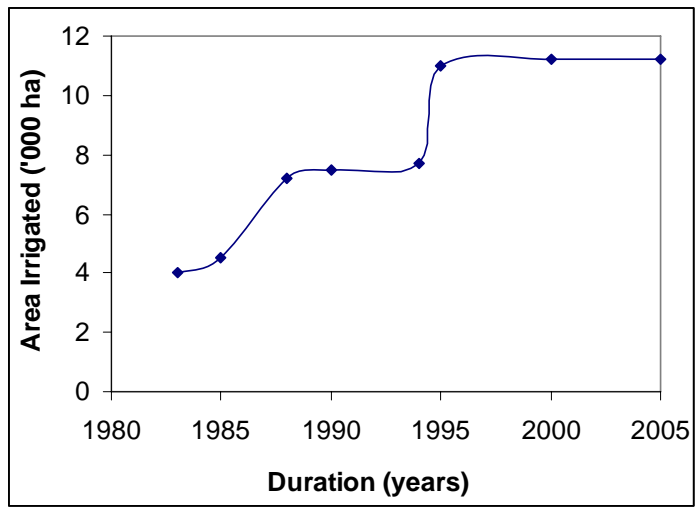


Fig 1: Extent of irrigated land in Ghana [Derived from Kyei-Baffour (1994) and FAO (2005)]

\section{Irrigation development in Ghana}

The history of irrigation development, the role of the state and the need for and the potential for irrigation as well as the capacity utilisation on existing schemes is examined.

\section{History of irrigation development}

Historical accounts trace irrigated agriculture in Ghana to a little over a century ago (Smith, 1969) but the practice on a small scale dates back to as early as 1880 in the Keta area on land above flood level between the lagoon and the sandbar separating it from the sea. This form of agriculture had to be adopted in Keta because natural conditions did not permit shifting cultivation as practised elsewhere in the country, thus intensive methods of cultivation by irrigation, manuring and crop rotation had to be used (Smith, 1969).

The first scheme that the government conceived was in 1920 as part of the then Winneba Water Supply Project (Smith, 1969). According to Agodzo and Bobobee (1994), some forms of shallow tubewell irrigation could also be identified in South-Eastern Ghana in the 1930's. The 1950's and early 1960's saw the development of some water schemes in the Guinea, Sudan and Coastal Savannah belts which accounted for about 240 earth dams and dug-outs in the north and about 66 in the Ho-Keta plains of the south purposely to provide water for domestic use, livestock and for dry season irrigated farming (Agodzo and Bobobee, 1994).

It was soon after independence in 1959 that the first national irrigation project, Dawhenya, was started but available records indicate that Asutsuare Irrigation Project was the first to be completed in 1967. Even though the records date irrigation in the country to about a century ago, it is clear that serious irrigation is a more recent phenomenon.

\section{History of management of irrigation}

Since formal or project-type irrigation began in post-independent Ghana, the management of projects have been in the hands of many government and quasi-government bodies. It is worthy to note that during the 1960 's, due to lack of the required expertise, the engineering input to the earlier irrigation facilities, that were meant to be conservation dams were rather low. This is evidenced in the rather small size of outlet pipes provided in dams constructed during the period mainly in the upper regions where climatic conditions are rather harsh (Wiafe and Nyaledzigbor, 1994). Thus the management of irrigation projects according to Gyarteng (1994) started with the Land Planning and Soil Conservation Unit in the Ministry of Food Agriculture (MOFA). Between 1965 and 1974, the unit was put under the Irrigation, Reclamation and Drainage Division of MOFA. This division metamorphosed into the Irrigation Department of MOFA from 1974-1977.

In contemporary times, irrigation has been managed by the Ghana Irrigation Development Authority (GIDA) which was established as a semi-autonomous public body by SMC (Supreme Millitary Council) Decree 85 in April 1977. Since then, the development and management of irrigation has been in the hands of GIDA. The responsibilities of GIDA, according to the Decree which was later amended in 1987 [(FAO, 1985 ) and (MOFA, 2006)], are:

To formulate plans for the development of irrigation

To develop the water resources of the country for irrigated farming, livestock improvement and fish culture

To execute comprehensive programmes for the effective use of irrigated lands in cooperation with the other agencies involved in providing extension services to farmers

To carry out land use planning in areas earmarked for development in order to conserve the soil and water resources in those areas, and

To layout the environs of each project area for housing purposes and for the provision of other social 
amenities

Cooperate with other agencies for safeguarding the health and safety of all people living within and around irrigation project areas

Undertake such other activities as are incidental or conducive to the discharge of its functions.

GIDA's basic responsibility is to develop the country's water resources for irrigated farming, livestock watering and aquaculture (MOFA, 2006).

\section{Justification for irrigation development}

There is no doubt that water is one of the most important inputs in agricultural production in Ghana apart from labour. More importantly, almost all agricultural production depends on natural rainfall. Because of this situation, crop yields are invariably poor when the rains fail, come too early or too late since there can literally be no control over this important input.

According to the FAO (1987), Ghana's population supporting capacities at low, medium and high levels of agricultural inputs are 20.06, 88.26 and 242.76 million respectively where the low level represent peasant farming and the high input level represent the more sophisticated and mechanised farming. It is therefore tempting to suggest that at the present population level of 20 million, rainfed agriculture at even low levels of inputs, can sustain the nation except during periods of drought. Also, less than adequate food is stored or processed for lean seasons and the distribution system for food products is rather inefficient. But even here, the current population is already close to this limit as revealed by the year 2000 population census. The population supporting capacities is on the assumption that all arable land is put under production which is not a realistic proposition in relation to environmental conservation needs.

Irrigation is also needed because of the odd dry year such as the one that occurred in 1983. The timeliness of rains is another issue that seriously affects agricultural operations. For example, the northern sector typified by the rainfall pattern in Navrongo in Figure 2a shows a unimodal rainfall of rather short duration and excessive evapotranspiration rates. The duration of the dry season in these areas tends to be distinct and long of nearly 7-8 months duration. The implication is that under rainfed agriculture farming is possible for a period of 4-5 months and the cultivation of crops with longer duration is impossible or risky without irrigation. The middle and southern sectors experience double maxima rainfall as typified by distributions in Kumasi and Accra in Figures $2 b$ and $2 c$ respectively. But even in these areas, there are distinct periods of dryness and the minor season tends to be rather short and unreliable. The coastal savanna belt records the smallest amount of rain nationwide.

There is also abundant evidence in Ghana as shown in Table 1 that crop yields are consistently greater in irrigated farming than under rainfed agriculture further reinforcing the argument for irrigation nationally.

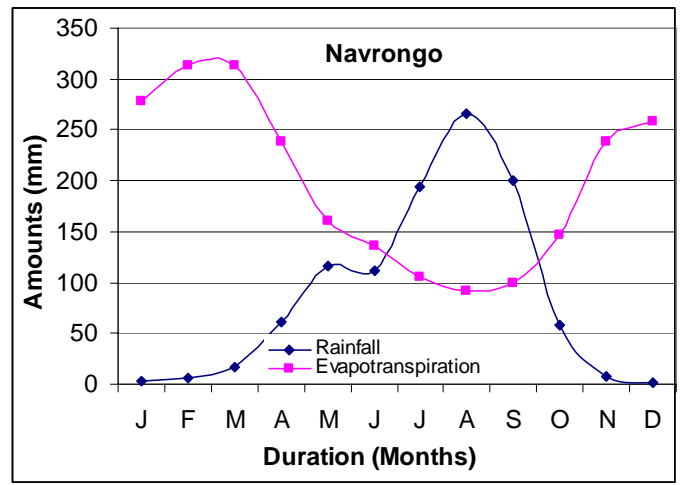

Fig. 2a: Mean rainfall and evapotranspiration trends for Navrongo [Derived from primary data from Meteorological Services Department (MSD) (1961-2004)]. 


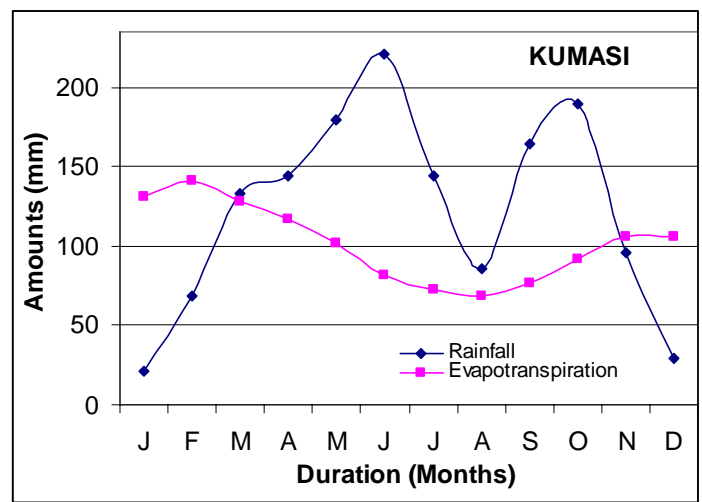

Fig. 2b: Mean rainfall and evapotranspiration trends for Kumasi [Derived from primary data from MSD (1961-2004)]

Table 1: Yields under traditional and irrigated agriculture in Ghana [Derived from World Bank report (1985) and Tweneboah (2000)]

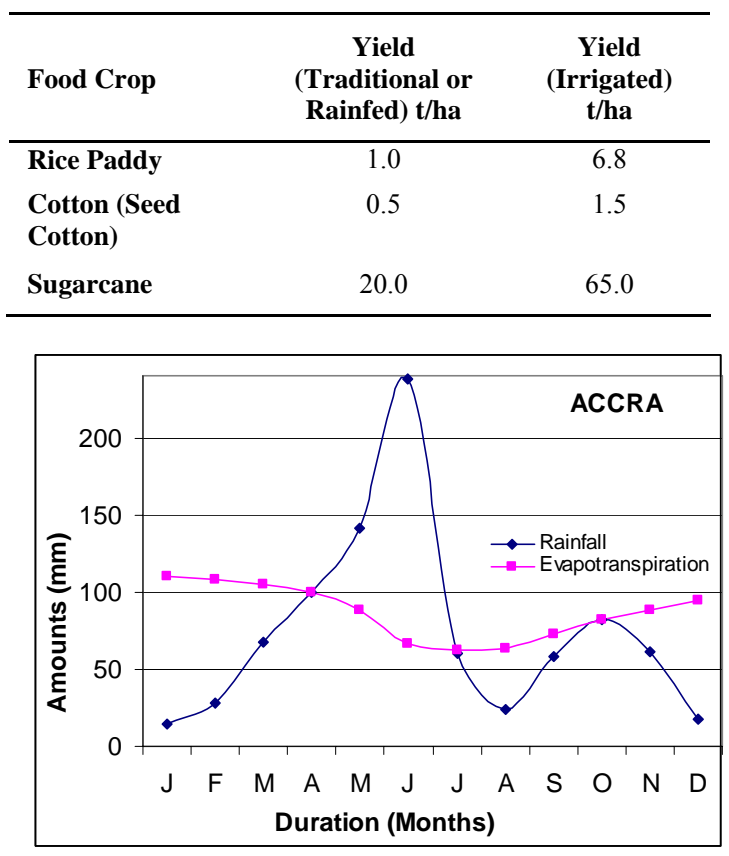

Figure 2c: Mean rainfall and evapotranspiration trends for Accra [Derived from primary data source collected from MSD (1961-2004)]

\section{Irrigable potential}

The irrigable land potential of Ghana is estimated at about 360,000 ha by Sant Anna (1997) of the FAO. Agodzo and Bobobee (1994) had earlier put the figure at over 500,000 ha. The FAO (2005) puts the current figure at over 1.9 million hectares. These estimates were based on whether the scheme was purely gravity, pumps and gravity, and pumps and sprinklers. Since the method of irrigation could be the more sophisticated and automated drip irrigation system, the popular surface irrigation system or even a watering can or a watering hose, irrigable potential becomes subject for debate based on how widely the definition of 
irrigation is applied in arriving at irrigable potential. Thus a dam designed to irrigate by gravity through an intricate network of canals can only irrigate low-lying lands in the area. This definitely precludes the possibility of pumping water uphill to irrigate the same piece of land through sprinklers and drip irrigation. The irrigation technologies available on the global market coupled with the almost adequate rainfall in most of the country make the concept of irrigable potential of Ghana difficult to define. Hence the extent of irrigable potential could be rather vague, hence the differing estimates. So it is the authors' contention that the irrigable potential of Ghana could be far higher than any of the projected figures. One can, however, conveniently estimate the irrigable potential of specific schemes already in existence as shown in Table 2.

Table 2: Irrigable potential of some irrigation projects [Compiled from FAO (1985), Agodzo and Bobobee (1994) and others]

\begin{tabular}{|c|c|c|c|c|c|}
\hline No. & $\begin{array}{c}\text { Irrigation } \\
\text { Project }\end{array}$ & $\begin{array}{c}\text { Irrigable } \\
\text { Potential (Ha) }\end{array}$ & No. & Irrigation Project & $\begin{array}{c}\text { Irrigable } \\
\text { Potential (Ha) }\end{array}$ \\
\hline 1 & Accra Plains & 178,200 & 21 & Kpong & 2,024 \\
\hline 2 & Adidome & 200 & 22 & Kpong Farms & 1,000 \\
\hline 3 & Afife & 1,012 & 23 & Mankessim & 324 \\
\hline 4 & Afram Plains & 202 & 24 & $\begin{array}{l}\text { Medium and small schemes } \\
\text { (Northern and Upper Regions) }\end{array}$ & 101,205 \\
\hline 5 & Akumadan & 810 & 25 & Nobewam & 215 \\
\hline 6 & Ashiaman & 235 & 26 & Okyereko & 121 \\
\hline 7 & Asutsuare & 2,000 & 27 & Pwalugu & 95,175 \\
\hline 8 & Aveyime & 8,000 & 28 & Passam & 1,250 \\
\hline 9 & Avu-Keta MPS) & 30,370 & 29 & Sata & 40 \\
\hline 10 & Avu-Keta (PF) & 40 & 30 & Small Schemes (ASIP) & 2,900 \\
\hline 11 & Ayensu & 3,500 & 31 & Subonpan & 20 \\
\hline 12 & Bontanga & 540 & 32 & Tamne & 500 \\
\hline 13 & Bui (MPS) & 32,400 & 33 & Tanoso & 1,200 \\
\hline 14 & Dawhenya & 486 & 34 & Tono & 2,632 \\
\hline 15 & Demon & 400 & 35 & Valley Bottom* & 600 \\
\hline 16 & Godenu & 20 & 36 & Vea & 1,417 \\
\hline 17 & Golinga & 100 & 37 & $\begin{array}{l}\text { Volta Lakeshore (Amate, } \\
\text { Lamassa, Kpando-Torkor) }\end{array}$ & 400 \\
\hline 18 & $\begin{array}{l}\text { Inland valleys } \\
\text { (IVRDP) }\end{array}$ & 4,600 & 38 & Weija & 2,267 \\
\hline 19 & Kikam & 27 & 39 & Yapei & 5,200 \\
\hline 20 & Komenda & 1,215 & 40 & Zongo-Macheri & 4,000 \\
\hline
\end{tabular}

*Some projects under valley bottoms have also been listed individually e.g. Nobewam

\section{Irrigation capacity utilisation}

The net irrigated area of about 11,000 ha on some existing 22 GIDA irrigation schemes (Sant' Anna, 1997) is nowhere near the irrigable potential of existing projects let alone that of the nation. In Figure 1, the extent of irrigation development in Ghana over the years is depicted and the trend is increasing which is likely to come from small scale projects such as the inland valleys irrigation development projects being promoted under the current administration of Ghana as well as the rehabilitation of some existing irrigation schemes. The lower net irrigated area is basically due to low capacity utilisation as exemplified in Table 3 . 
Table 3: Irrigation capacity utilisation of selected irrigation projects

\begin{tabular}{lccc}
\hline \multicolumn{1}{c}{$\begin{array}{c}\text { Irrigation } \\
\text { Project }\end{array}$} & $\begin{array}{c}\text { Irrigable } \\
\text { Potential (HA) }\end{array}$ & Net Irrigated (HA) & $\begin{array}{c}\text { Capacity Utilisation } \\
\text { (\%) }\end{array}$ \\
\hline Afife & 1,012 & 800 & 79 \\
Akumadan & 810 & 65 & 8 \\
Asutsuare & 2,000 & 216 & 11 \\
Bontanga & 540 & 470 & 87 \\
Dawhenya & 486 & 191 & 39 \\
Kpong Farms & 1,000 & 0 & 0 \\
Nobewam & 215 & 40 & 19 \\
Tono & 2,632 & 800 & 28 \\
Vea & 1,417 & 400 & 28 \\
Weija & 2,267 & 220 & 10 \\
TOTAL & $\mathbf{1 2 , 3 7 9}$ & $\mathbf{3 2 0 2}$ & $\mathbf{2 5 . 8 7}$ \\
\hline
\end{tabular}

The low capacity utilisation gleaned from reconnaisance surveys conducted around irrigation projects nationwide is attributable to factors outlined below:

Lack of finance to fully develop the area as originally conceived

Removal of subsidies on agriculture making imported rice (often subsidized abroad) sell at cheaper prices locally

- Irrigation water was formerly offered free as a social service but since 1980 , farmers have been made to pay for water charges at rates fixed from time to time. The canals and drains are mainly cleared and maintained by the farmers

- Agriculture is predominantly rainfed, so during the major rainy season farmers naturally prefer rainfed farming which they are very adept at and besides the rainwater is free to them. This stems also from the lack of irrigation culture in the country

- Marketing of produce is often a problem. This is an area controlled by middle women who often through calculated efforts (like controlling the number of vehicles used to convey the produce) offer ridiculously low prices to farmers. In such situations, farmers who do not break even may not be able to continue farming. This is more of a problem at tomato growing areas like Akumadan. There is also no minimum guaranteed prices for such products which are often left to market forces for pricing

- Lack of food processing and storage facilities as well efficient distribution systems mean bumper harvests often go waste at great cost to the farmer

- There is also low logistic support from central government as well as minimal commercial sector involvement

- The lending policies of banks is also a contributory factor since banks are unwilling to offer loans to poor peasant farmers without any colateral. But repayment of loans by farmers is also very uncomplimentary

- Peculiar problems such as clusters of problem soils e.g. sandy soils which do no favour basin irrigation of rice at some parts of Nobewam, salt affected soils at Afife and old pumps which frequently breakdown and lack the necessary capacity to deliver the required flows as happens at Akumadan (Kyei-Baffour, 1994)

- The very approach of implementing irrigation projects in the past, that is the top-down approach, making farmers see irrigation as government project thus giving them no sense of responsibility

- Outbreak of pests and diseases without immediate solution because of poor linkage of projects with research institutions eg. tomato disease at ICOUR 
- General breakdown of irrigation infrastructure due to lack of repairs e.g. primary canals at Tono

- Inadequate technological know-how of Ghanaians on irrigation and

- High energy cost e.g. electricity charges for electric pumps

\section{Broad policy considerations needed to improve irrigation}

The current under-pinnings of the national economy towards free market policies is likely to be the guiding principle for irrigation development in the foreseeable future. Whether irrigation can survive this policy will to a large extent depend on the policy interventions that will be put in place in the area of project objectives, cost, management, research, training and extension and marketing.

\section{Objectives of irrigation projects}

Properly designed and constructed water distribution structures in irrigation are ultimately aimed at food production, hence if this objective is defeated, then that project is merely an exercise in futility becoming inimical to the economic and environmental health of the nation. As a broad policy goal, irrigation should in principle ensure consistent food supplies, halt occassional famine, stabilise production, allow the commercial production of food and fibre for the local market and for export, allow for increased possibilities of crop diversification that favour high value crops and possibly become the linchpin for the industrial takeoff of Ghana and the attainment of food security.

In order to maximise productivity on irrigated lands, existing and future projects must aim at the maximisation of cropping intensity and a drive towards the minimisation of the cost of production and the maximisation of employment as a socio-economic benefit. To achieve these laudable objectives through irrigation, water must be available in sufficient quantities for the development of schemes, the cost of harnessing it must be reasonable, agriculture must also be made attractive particularly to the young in terms of its economic benefits and the reduction of drudgery through the introduction of less arduous and backbreaking means of production. Appropriate expertise must also be available for feasibility studies, design, implementation, monitoring and evaluation, and the general management of schemes.

The development and management of irrigation must also be environmentally friendly in order to avert any form of contamination and degradation of land and water resources. Projects must therefore be subjected to pre- and post-project environmental impact assessment (EIA). This will include making concerted efforts through research, training and extention to significantly reduce the amount of irrigation water used by improving irrigation efficiencies which are currently low. This is because any excess water applied is a source of environmental anxiety.

\section{Scale of irrigation}

Irrigation projects in Ghana are generally categorised as small, medium or large based primarily on size. Sizes of up to 200 ha are regarded as small and anything greater than 1,000 ha as large with anything inbetween the two (200-1,000 ha) as medium. It is proposed that the level of management could be factored into the classification of schemes. For example, a small scale project must also be wholly-owned and managed by the farmer or group of farmers. In the same vein, projects jointly owned and managed by the state through GIDA and farmers could be regarded as medium. Bigger projects could then be those large stated-owned projects managed by the state or quasi-government agencies. Based on this reclassification, small scale irrigation can only be found on private farms and their numbers are virtually insignificant. The whole idea is to put the irrigation development philosophy in the hands of the farmer through the introduction of appropriate small scale irrigation technologies and vigorous extension policies, this way, half the battle over the cost of irrigation and management would have been won.

\section{Cost of irrigation}

One issue which generates a lot of pessimism about irrigation in Ghana is the issue of cost. According to the World Bank (1985), the budgetary expenditures on irrigation are substantial compared to its limited role in overall agriculture. This they contend is far out of line with the economic returns from irrigation. It is also 
their contention that the cost per ha of large scale dam schemes in Ghana are above $\$ 15,000$. Elsewhere in Africa, e.g. the White Nile Pump Irrigation scheme in Sudan and the Central Tunisia Irrigation project cost $\$ 1,000 /$ ha and $\$ 3,400 /$ ha respectively which are much lower than the figures for Ghana. Also, the Rajasthan or the Stage Irrigation scheme in India cost a mere $\$ 450 /$ ha. This proves that cost can be reduced. Data on irrigation cost in Ghana is patchy but the generally higher cost of irrigation are due to (World Bank, 1985 and FAO, 1985):

Inadequate local expertise in planning, design and construction of irrigation projects and hence the involvement of expensive expatriate expertise at all stages of the project cycle at the early stages of nationhood.

Inadequate feasibility studies leading to costly design changes during construction.

Costly involvement in construction of on-farm works, which should be handled by farmers.

Delays in obtaining imported inputs (owing to foreign exchange shortage during the 1960's to the 1980's) which caused delays in the construction of projects.

Unsuitable and avoidable mechanisation of construction operations where labour-intensive techniques could be developed and used.

The use of tied external funds to build irrigation network often involving additional supervision and administrative costs and the procurement of non-standard equipment requiring special maintenance and service arrangements.

The relative inflexibility in project construction due to agreements entered into by governments and lending agencies.

The use of foreign firms for construction and their practices like over-designing to preserve their reputation since they have insufficient knowledge of local conditions and the tendency to apply some amount to their bids to cater for risks they perceive in operations in Ghana.

In light of the above, can irrigation in Ghana ever become a self-sustainable subsidy-free activity? It is the authors' contention that this is unattainable on present schemes since no attempt is ever made to recoup investment cost and only part of the operational cost is recovered through water charges. GIDA is also a subvented organisation and staff are paid from the consolidated fund.

There is therefore the need to look at options for curtailing cost. There must be effective and efficient cost recovery and sharing policies and some operations which are best done by farmers must be left to them. International lending/insurance agencies need to re-examine their lending/insurance policies since Ghana is relatively peaceful compared with some other African countries. As much as possible, local expertise must be used and independent bodies or individuals in the country, outside GIDA should be consulted for independent opinions about designs emanating from GIDA.

Local contractors can be given appropriate training to execute irrigation projects and local manpower must be given sufficient training and exposure to completely handle all aspects of irrigation projects. Data collection and dissemination need to be taken seriously to avoid costly over-design of projects. Small scale irrigation technologies like tubewell irrigation and simple manual or small scale pumps like chain and washer, hydraulic pumps, treadmill pumps, archemedian screws and counterpoise bucket lifts for protective irrigation must be explored and popularised through extension.

\section{Irrigation management}

Irrigation management has two major components which are the normal managerial functions and irrigation water management:

\section{Normal managerial functions}

The normal managerial function is the overall direction and coordination of the decision-making process which usually involves monitoring those factors which influence the irrigation system performance namely resources (i.e finance, manpower and equipment), skills (i.e technical, management and communication 
know-how) and the motivation of staff (i.e salaries, bonuses, material and non-material incentives, promotions, job satisfaction and recognition of exceptional contributions by individuals). This function is generally performed by GIDA but GIDA being a parastatal body must strive to be efficient by maintaining a tighter control over budget and staffing, maintaining adequate technical expertise in all departments of irrigation and also ensuring higher productivity on projects. According to Sonou (1988), related functions on projects e.g. irrigation and agronomy must be closely linked. Policy at governmental level on irrigation must be consistent and management should learn to delegate authority. Funds for running projects must be available and projects must be left free of political interference whilst at the same time giving irrigation priority at the highest political level.

Certain preconditions must be fulfilled to ensure good management. These are:

1. an adequately designed irrigation system

2. an appropriate organisational structure

3. the putting in place of a consistent and clearly defined management system (e.g. detailed management procedures, job descriptions, information and monitoring systems)

4. policies on staff recruitment, production levels and attractive salary packages

5. adequate financial support for recurrent expenditure, either from central government and/or from water and other charges

6. an effective legal framework for the enforcement of water distribution rules or the abstraction of water (Sonou, 1988) and

7. irrigation projects must be accorded priority at the highest political level.

\section{Irrigation water management}

Water management seems to be the achilles heel of irrigation systems nationwide. The adoption of appropriate and holistic water management policies will lead to substantially increased crop production with regards to yield per hectare, which on the average is higher than under rainfed conditions. For example, an important water management activity covers the area of water distribution (i.e. system operation), systems maintenance and irrigation extension. Important flow measuring devices incorporated in canals (e.g. Bontanga) are hardly used to advantage, hence more often than not irrigation efficiencies are not known. Thus, instead of sticking to design flows which are often based on weak database, attempts must be made to study some of the soil-crop-water relationships to improve water management. Simple devices like the raingauge and class A pan can be installed at the inception of each project to aid irrigation scheduling. Simple moisture sensing devices like the gypsum block and flow measurement devices can be constructed locally to aid water management.

Proper land preparation is needed to ensure efficient water management for the predominant surface irrigation methods. For example, a levelled field can make efficient use of expensive water and save irrigation time. For example, water will run to the end of every row (as in furrow irrigation) and each plant will conceptually receive its share if the land is levelled correctly. There will be no low or high spots to drown (i.e. drainage problems) or burn (i.e. moisture stress problems) out crops respectively. Similarly on a well-graded field, each crop row will drain since there should be no irrigation without drainage as a matter of principle. There will be no pockets or depressions to collect water and drown out crops. Proper water management will lead to less wastage and as a sequel reduce environmental hazards like the rise of water tables, water logging, leaching of nutrients, erosion, as well as water-borne and water-related diseases.

\section{Policy shifts needed to improve and promote irrigation}

At the Nobewam Irrigation Project site, irrigation is done essentially during the major rainy season because the feasibility studies suggested a perennial River Annum which has turned out to be unreliable. Thus monitoring and evaluation seem to be a neglected activity which is verifiable on most schemes. They should become an integral part of irrigation management but this will require accurate record keeping. GIDA will 
need to set up a monitoring and evaluation unit made up of engineers, sociologists, crop and soil scientists and a few other related professionals. A computer is a necessity for such a unit and their findings must be fed back to improve irrigation management.

Currently, irrigation is recognised as a multidisciplinary activity. Clothier (1989) sees irrigation science as a loose confederation of disparate disciplines whose unity arises out of a common study of the limiting role of water in the growth and development of plants of economic value. According to Ferguson (1990) irrigation management research has emphasised physical and biological processes, drawing from fields like agronomy, engineering and hydrology. However, the interdisciplinary nature of the field has gained greater recognition and research has been extended to include the social sciences. Ferguson (1990) further argues that because the latter human elements of irrigation have received less attention in the past, the social and institutional aspects of water management are still poorly understood. Thus, instead of engineers and agronomists jostling for supremacy on projects (Kyei-Baffour, 1994) and some professionals seeing themselves as the sine qua-non of irrigation development and management (Wiafe and Nyaledzigbor, 1994), functions must be unambiguously defined to complement one another.

A master plan on the water resources of the country including smaller and non-perennial streams and groundwater resources must be drawn up to aid planning. A water budget for the nation is also necessary to ensure effective planning. This is advocated because according to Ferguson (1990) reliable quantitative information on water management is necessary to avoid costly mistakes in design, construction and operation of irrigation systems. A strong database and research will ensure improved water management, reduced project implementation and lower operation and maintenance cost. Research must also be intensified in the area of fish farming on irrigation schemes, erosion control to prevent siltation of dams, water management on farms and measurement of field water application and irrigation efficiencies.

Another area requiring research attention is cropping intensity and crop yields on projects. For example, yield of rice in Japan and South Korea is estimated at 6 t/ha or higher (Tanaka, 1994) whilst figures in Ghana is about half as much. Therefore, research must aim at improved yields in irrigated ecologies. The impacts of irrigation on food production and the environment also need some study. The cost of irrigation must also be scrutinized with a view to reducing cost. The establishment of an Irrigation Development Research Centre at Ashiaman is laudable but the centre needs to have strong linkages with the universities and other research institutions.

An important missing link in irrigation development and management in Ghana is the lack of local capacity to execute irrigation projects completely. This is partly due to the absence of a fully-fledged programme in irrigation in any of the nations tertiary institutions. It is therefore suggested that a postgraduate programme in irrigation should be run locally to train highly qualified professionals to plan, implement and man irrigation projects taking the peculiar Ghanaian situation into context. This can be done at the College of Engineering in Ghana at the Kwame Nkrumah University of Science and Technology (KNUST) by the Departments of Agricultural Engineering and Civil Engineering with inputs from Economics, Sociology, Soil Science, Crop Science and other applied sciences, both soft and hard. Such a programme will help intensify research in irrigation. Short courses could also be run for irrigation practitioners, that is managers and farmers. Such a programme stands a good chance of attracting students from sister African countries since training in irrigation at the postgraduate level is often done abroad in most developing countries except for countries like Nigeria and Kenya.

\section{CONCLUSION AND RECOMMENDATIONS}

Prospects for irrigation development in the future are bright provided it will be accorded the required priority at the highest political level. The issue of cost can be contained and irrigation made affordable to the small scale farmer through simple technologies. The database for irrigation must be improved through proper record keeping on projects and research. Research must also aim at improving yields and optimising water usage on projects. Local capacity to completely man irrigation projects must also be developed by running good irrigation training programmes at KNUST. 


\section{REFERENCES}

Agodzo, S. K. and Bobobee, E. Y. H. (1994). Policy issues of irrigation in Ghana: 1960-1990. Proceedings of the XIIth World Congress on Agricultural Engineering, Milano, 28 August-1 September 1994. CIGR Vol. 1 pp 335-343.

Clothier, B. E. (1989). Research imperatives for irrigation science. Journal of Irrigation and Drainage 115(3): 421-448.

FAO. (2005). Aquastat: Country data on Ghana. FAO, Rome. Cited from www.fao.org/ag/agl/aglw/aquastat/countries/ghana/index.stm on 22 August 2005.

FAO. (1987). Consultation on irrigation in Africa. Irrigation and Drainage paper 42. FAO, Rome.

FAO. (1985). Survey of irrigation development costs in Nigeria, Ghana, Liberia, Sierra Leone and the Gambia. FAO, Rome.

Ferguson, C. A. (1989). Modelling water utilization in large-scale irrigation systems. A qualitative response approach. Water Resources Bulletin (AWRA). 25(6): 1199-1204.

Gyarteng, O. K. (1994). Policy issues of irrigation in Ghana. In proceedings of the $1^{\text {st }}$ National Conference on Agricultural Engineering at the Department of Agricultural Engineering, KNUST, Kumasi from 2529 September 1994. (eds Dzisi, K. A., Twum, A. and Lamptey, D. L.) pp 47-50.

Kyei-Baffour, N. (1994). Future irrigation prospects and actions in Ghana. In proceedings of the $1^{\text {st }}$ National Conference on Agricultural Engineering at the Department of Agricultural Engineering, KNUST, Kumasi from 25-29 September 1994. (eds Dzisi, K. A., Twum, A. and Lamptey, D. L.) pp 65-75.

Memuna, M. M. and Cofie, O, O. (2005). Effects of farming practices on the performance of rice (Oryza sativa) in selected farms of Ashaiman Irrigation Project. In Hunger without Frontiers. (Eds. Bobobee, E. H. Y. and Bart-Plange, A.). GSAE/WASAE, Kumasi, Ghana p.244-254.

Ministry of Food and agriculture (MOFA). (2006). Draft national irrigation policy, strategies and regulatory measures. MOFA/FAO, Accra, Ghana.

Ministry of Food and agriculture (MOFA). (1991). Agriculture in Ghana: Facts and Figures. MOFA, Accra, Ghana.

Smith, M. (1969). A historical sketch of water resources development in Ghana. WRI/CSIR, Accra, Ghana.

Sonou, M. (1988). Management issues of irrigation in Africa. Paper presented at Departmental Seminar, Department of Agricultural Engineering, KNUST, Kumasi.

Tanaka, A. (1994). Irrigated rice and sustainable agriculture. Paper presented during international seminar on rice: "Towards rice self-sufficiency in Ghana", 7 June 1994 Akosombo, Ghana.

Tweneboah, C. K. (2000). Modern agriculture in the tropics with special reference to Ghana: Food crops. Co-World Publishers, Ghana.

Wiafe, K. and Nyaledzigbor, K. (1994). The role of the Civil Engineer in irrigation development in Ghana. Departmental Seminar, Department of Civil Engineering, KNUST, Kumasi.

World Bank. (1985). Ghana agricultural sector review report. No. 5366-GH, Washington. 